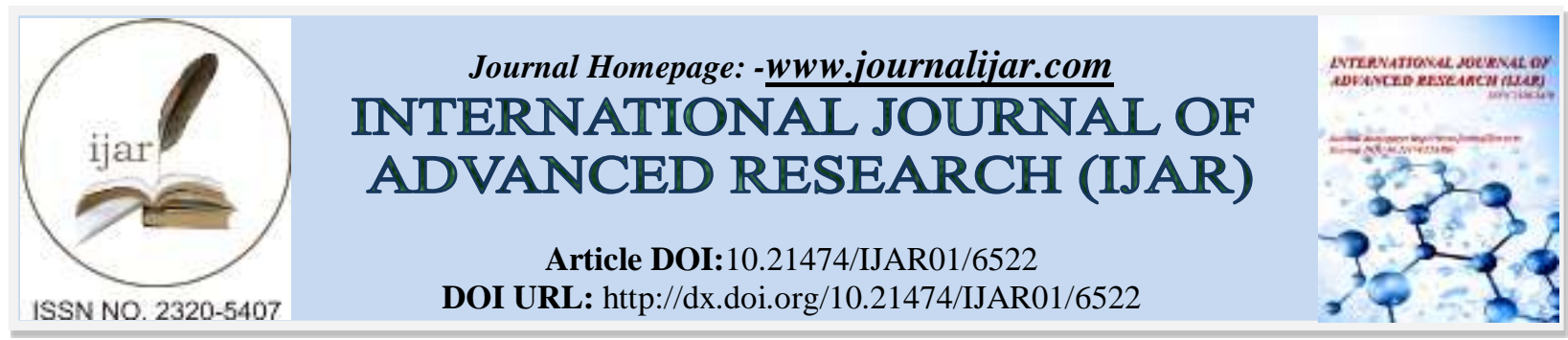

RESEARCH ARTICLE

\title{
ANATOMICAL MEASUREMENTS OF GREAT SAPHENOUS VEIN AND SUPERFICIAL FEMORAL VEIN BY COLORED DUPLEX ULTRASOUND.
}

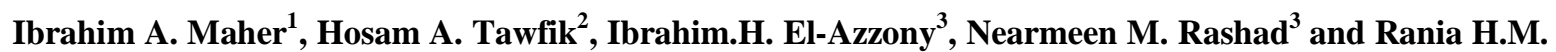 Soliman ${ }^{3}$.}

1. Anatomy \& Embryology Department, Faculty of Medicine, Zagazig University, Zagazig, Egypt.

2. Vascular surgery Department, Faculty of Medicine, Zagazig University, Zagazig, Egypt.

3. Internal Medicine Department, Faculty of Medicine, Zagazig University, Zagazig, Egypt.

\section{Manuscript Info}

\section{Manuscript History}

Received: 13 December 2017

Final Accepted: 15 January 2018

Published: February 2018

Keywords:-

saphenous vein, duplex ultrasonography, femoral veins, MI.

\section{Abstract}

Vascular ultrasonography has an important role in the diagnosis and management of venous disease. The venous system, however, is more complex and variable compared to the arterial system due to its frequent anatomical variations. Thus, the aim of our study was to assess the great saphenous vein and superficial femoral vein at different levels and its relation to age, sex and body mass index in Egyptian population by noninvasive colored duplex ultrasound.

Methods: Our study was cross- sectional descriptive study comprised 75 subjects with one hundred fifty- limbs. We classified studied subjects to lean and obese group according to body mass index (BMI). The diameter of the greater saphenous vein and femoral vein in $\mathrm{mm}$ were measured with duplex ultrasound longitudinal imaging in three different levels.at both lower limbs and in standing as well as supine position.

Results: Obese patients had significantly higher diameter $(\mathrm{mm})$ of the femoral vein compared to lean controls. However, the diameter (mm) of great saphenous vein of the both lower limb in the different levels (1 ${ }^{\text {st }}$ Standing, $2^{\text {nd }}$ Standing 3 rd Standing $1{ }^{\text {st }}$ Supine $2{ }^{\text {nd }}$ Supine and $3{ }^{\text {rd }}$ Supine) were non-significantly higher in obese women compared to lean subjects. Moreover, there were significantly higher diameter (mm) of great saphenous vein at $1{ }^{\text {st }}$ Standing, $2^{\text {nd }}$ Standing 3 rd Standing in both lower limbs compared to corresponding levels in Supine position. By using ROC curve test, we found that the highest area under the curve (AUC) (0.797, C.I 0.669 - 0.924), sensitivity $(96.1 \%)$ and specificity $(63 \%)$ were of femoral vein diameter $(\mathrm{mm})$ with cutoff $(7.15$ $\mathrm{mm}$ ). linear regression analysis test found that, the diameter of femoral vein $(\mathrm{mm})$ was only independently correlated with BMI.

Conclusion: obese subjects had significantly higher diameter ( $\mathrm{mm}$ ) of the femoral vein compared to lean control. However, the diameter (mm) of great saphenous vein of the both lower limb in the different levels were non-significantly higher in obese women compared to lean subjects.

Copy Right, IJAR, 2018,. All rights reserved. 


\section{Introduction:-}

The greater saphenous vein (GSV) is the longest vein in the body. the anatomy of the greater saphenous venous system in current standard texts is usually described as a continuous single trunk in the medial and lateral accessory branches originates from the anterior aspect of the medial malleolus and runs along the tibial aspect of the medial calf before crossing the knee finishing in the groin. Moreover, below the knee there is a posterior accessory branch that invariably rejoins the main trunk above the ankle [1]

The surgical anatomy of the saphenous venous system is particularly relevant and have recently become even more significant because of the importance of this vein as an approach to each in situ bypass procedure; hence, accurate knowledge of this system has provided a major advance in the simplification of such procedure. [1].

Vascular ultrasonography has an important role in the diagnosis and management of venous disease. The venous system, however, is more complex and variable compared to the arterial system due to its frequent anatomical variations The diagnosis and treatment of chronic venous diseases has undergone a quantum leap forward in recent decades[2] thanks to advances in understanding made possible by technical improvements in ultrasound equipment, diagnostic techniques,[3] and communication standards related to research in anatomy and pathophysiology[4].Currently, high definition echo color Doppler (HD-ECD) is considered the gold standard for diagnosis of the venous system[5].

Venous mapping gained by using HD-ECD provides an accurate graphic representation of the deep and superficial venous systems, it is an anatomic paper pattern of the lower limbs venous system based on the ultrasound study [6] and the performance of venous mapping is now considered essential for correct management of venous diseases. [7]. In fact, such an evaluation leads to improved knowledge about the hemodynamics of the venous system. This is important in order to ameliorate the decision about further treatment of venous diseases, for example, in the case of evaluating the real necessity to strip the saphenous vein in case of its insufficiency.

The aim of our study was to assess the great saphenous vein and superficial femoral vein at different levels and its relation to age, sex and body mass index in Egyptian population by noninvasive colored duplex ultrasound.

\section{Subjects and methods:-}

This cross- sectional descriptive study comprised 75 subjects with one hundred fifty- limbs were examined. The studied subjects were recruited from the outpatient clinics of the vascular surgery and Internal Medicine departments as well as Anatomy \& Embryology at the Zagazig University hospitals. The Ethics Committee of Faculty of Medicine, Zagazig University approved this work. All participants assigned informed written consent prior to their inclusion., patients were over 18 years of age

All participants underwent complete history taking, thorough clinical examination included anthropometric variables including BMI was calculated as weight in $\mathrm{kg} /$ height in (meters). None of the participants had history of varicose vein surgery or intervention, saphenous harvesting as well as venous disease at lower limb (deep venous thrombosis, superficial thrombosis and varicose vein). Also, any abnormalities detected clinically or by the duplex ultrasound [reflux- thrombosis - C.V.M. (Congenital Venous Malformation) were excluded from the study.

\section{Duplex ultrasound of the Great saphenous vein and superficial femoral vein:-}

Measurement of diameters of the GVS at different levels and superficial femoral vein was performed using colourcoded duplex ultrasound examinations were performed with (Esaote mylab 50 Xvision colour-coded duplex scannerfitted ultrasonography) in B-mode with a 7.5-MHz linear probe for lean subjects but for fat patients, the 3-5 $\mathrm{MHz}$ convex transducer was used. We measured the superficial femoral vein just distal to the saphenofemoral junction (SFJ).

The GSV was examined in both standing and supine position. As regard the standing position, volume increase due to shift of blood from the central veins to the venous system of the legs after $5 \mathrm{~min}$. Regarding the supine position, subjects were scanned in 45 degrees of reversed trendelenburg to discard the possibility of thrombosis or reflux in any veins in this system as described by many other authors. [8-10]. Assessment of the superficial venous system 
and perforator veins was done while the studied subject was standing on a two-step ladder holding himself in the upright position [11].

The GSV in the right lower limb (RLL) and left lower limb (LLL) were analyzed in detail from the dorsomedial area of the foot to its junction with common femoral vein in the groin with the B-mode and spectral curve of ultrasound. The studied levels were described as the following; the first level to be studied was in the inguinal area, $2 \mathrm{~cm}$ from the SFJ where the vein was visible without any curvature. the second level located in the thigh equally distant from the first level and the third level (the medial face of the knee in the interarticular area). The veins were measured in millimeter with ultrasound longitudinal image.

\section{Statistical analysis:-}

Statistical analyses were performed using the Statistical Package for the Social Sciences for Windows (version 21.0; SPSS Inc., Chicago, IL, USA). Data were expressed using descriptive statistic (mean \pm standard deviation) and were analyzed using " $t$ " test. Pearson correlation coefficient was used to assess the association between BMI, age and sex with the diameter $(\mathrm{mm})$ of the great saphenous vein of both right and the left lower limb in studied subjects. Receiver operating characteristic (ROC) analysis was performed to assess the cutoff values of great saphenous vein at different levels in both right and left leg at standing position as well as at supine position to differentiate between lean and obese patients. A linear regression analysis was to test the influences of the main independent variables against BMI (dependent variable) in obese subjects. We considered $P$ to be significant at $<0.05$ with a $95 \%$ confidence interval (CI).

\section{Results:-}

Our study was cross- sectional descriptive study comprised 75 subjects with one hundred fifty- limbs. We classified studied subjects to lean and obese group according to BMI. In the lean group $(n=51), 54.9 \%$ were male $(n=28)$ and $45.1 \%$ were female $(n=23)$, their mean age was $41.86 \pm 2.39$ year and their BMI were $26.5 \pm 2.91$. In obese group $(n=24)$ group,41.6\% were male $(n=10)$ and $58.4 \%$ were female $(n=14)$, their mean age was $56.05 \pm 2.21$ year. and their BMI was 33.64 \pm 2.59 .

Diameter (mm) of the femoral vein and the great saphenous vein of the both lower limb in the different levels of all studied subjects were summarized in Table 1

Obese patients had significantly higher diameter $(\mathrm{mm})$ of the femoral vein compared to lean controls. However, the diameter $(\mathrm{mm})$ of great saphenous vein of the both lower limb in the different levels $\left(1{ }^{\text {st }}\right.$ Standing, $2^{\text {nd }}$ Standing 3 rd Standing $1{ }^{\text {st }}$ Supine $2{ }^{\text {nd }}$ Supine and $3{ }^{\text {rd }}$ Supine) were non-significantly higher in obese women compared to lean subjects. $(P<0.001)$.

Table 1:- Diameter $(\mathrm{mm})$ of the femoral vein and the great saphenous vein of the both lower limb in the different levels of all studied subjects.

\begin{tabular}{|c|c|c|c|c|c|c|}
\hline \multirow[t]{2}{*}{ Diameter } & \multicolumn{2}{|c|}{$\begin{array}{c}\text { Lean Group } \\
\mathrm{N}=51,(\text { mean } \pm \mathrm{SD})\end{array}$} & \multicolumn{2}{|c|}{$\begin{array}{c}\text { Obese Group } \\
\mathrm{N}=24,(\text { mean } \pm \mathrm{D})\end{array}$} & \multirow[t]{2}{*}{ P 1} & \multirow[t]{2}{*}{$\mathrm{P} 2$} \\
\hline & RLL & LLL & RLL & LLL & & \\
\hline $1^{\text {st }}$ Standing & $5.46 \pm 1.121$ & $5.7 \pm 1.12$ & $5.86 \pm 1.215$ & $6.1 \pm 1.215$ & 0.167 & 0.164 \\
\hline $2^{\text {nd }}$ Standing & $3.45 \pm 0.80$ & $3.78 \pm 0.80$ & $3.77 \pm 0.922$ & $4.0 \pm 0.922$ & 0.140 & 0.143 \\
\hline $3^{\text {rd }}$ Standing & $2.6 \pm 0.761$ & $3.32 \pm 0.76$ & $2.9 \pm 0.803$ & $3.55 \pm 0.80$ & 0.239 & 0.248 \\
\hline $1{ }^{\text {st }}$ Supine & $5.32 \pm 1.183$ & $5.43 \pm 1.152$ & $5.52 \pm 1.33$ & $5.6 \pm 1.286$ & 0.521 & 0.559 \\
\hline $2^{\text {nd }}$ Supine & $3.17 \pm 0.953$ & $3.3 \pm 0.907$ & $3.3 \pm 1.1$ & $3.4 \pm 1.041$ & 0.413 & 0.465 \\
\hline $3{ }^{\text {rd }}$ Supine & $2.28 \pm 0.866$ & $2.56 \pm 0.77$ & $2.44 \pm 0.99$ & $2.65 \pm 0.85$ & 0.485 & 0.635 \\
\hline Femoral vein & \multicolumn{2}{|c|}{$5.97 \pm 1.018$} & \multicolumn{2}{|c|}{$7.36 \pm 1.47$} & \multicolumn{2}{|c|}{$<0.001 *$} \\
\hline
\end{tabular}

RLL, right lower limb; LLL, left lower limb. P1 Significant P value as compared between RLL of obese with RLL of lean group.P2 Significant P value as compared between LLL of obese with LLL of lean group. *Significant P $<$ 0.05 . 
Pearson correlation between BMI, sex, age and the femoral vein as well as the great saphenous vein diameter $(\mathrm{mm})$ of the both lower limb in the different levels in studied group.

Regarding BMI, our results demonstrated highly significant positive correlations with great saphenous vein of the both lower limb in the different levels $\left(1^{\text {st }}\right.$ Standing, $2^{\text {nd }}$ Standing 3 rd Standing, $1{ }^{\text {st }}$ Supine, $2{ }^{\text {nd }}$ Supine and $3{ }^{\text {rd }}$ Supine as well as femoral vein. Interestingly, among these levels, the highest positive correlation found between femoral vein and BMI, $(P<0.001)$ (Table 2).

Table 2:- Pearson correlation between BMI, sex, age and the femoral vein as well as the great saphenous vein diameter $(\mathrm{mm})$ of the both lower limb in the different levels in studied group.

\begin{tabular}{|l|l|l|l|l|l|l|}
\hline \multirow{2}{*}{ level } & \multicolumn{2}{|c|}{ BMI } & \multicolumn{2}{c|}{ Sex } & \multicolumn{2}{c|}{ Age } \\
\cline { 2 - 7 } & \multicolumn{1}{|c|}{$\mathrm{r}$} & \multicolumn{1}{c|}{$\mathrm{p}$} & \multicolumn{1}{c|}{$\mathrm{r}$} & $\mathrm{p}$ & $\mathrm{r}$ & $\mathrm{p}$ \\
\hline $1^{\text {st }}$ Standing of RLL & 0.262 & $<0.05^{*}$ & 0.675 & $<0.001^{*}$ & 0.277 & $<0.05^{*}$ \\
\hline $2^{\text {nd }}$ Standing of RLL & 0.296 & $<0.001^{*}$ & 0.677 & $<0.001^{*}$ & 0.315 & $<0.001^{*}$ \\
\hline $3^{\text {rd }}$ Standing of RLL & 0.270 & $<0.05^{*}$ & 0.652 & $<0.001^{*}$ & 0.291 & $<0.05^{*}$ \\
\hline $1^{\text {st }}$ Supine of RLL & 0.266 & $<0.05^{*}$ & 0.458 & $<0.001^{*}$ & 0.276 & $<0.05^{*}$ \\
\hline $2^{\text {nd }}$ Supine of RLL & 0.298 & $<0.001^{*}$ & 0.450 & $<0.001^{*}$ & 0.317 & $<0.001^{*}$ \\
\hline $3^{\text {rd }}$ Supine of RLL & 0.273 & $<0.05^{*}$ & 0.415 & $<0.001^{*}$ & 0.293 & $<0.05^{*}$ \\
\hline $1^{\text {st }}$ Standing of LLL & 0.264 & $<0.05^{*}$ & 0.675 & $<0.001^{*}$ & 0.273 & $<0.05^{*}$ \\
\hline $2^{\text {nd }}$ Standing of LLL & 0.295 & $<0.001^{*}$ & 0.677 & $<0.001^{*}$ & 0.325 & $<0.001^{*}$ \\
\hline $3^{\text {rd }}$ Standing of LLL & 0.270 & $<0.05^{*}$ & 0.652 & $<0.001^{*}$ & 0.294 & $<0.05^{*}$ \\
\hline $1^{\text {st }}$ Supine of LLL & 0.261 & $<0.05^{*}$ & 0.469 & $<0.001^{*}$ & 0.274 & $<0.05^{*}$ \\
\hline $2^{\text {nd }}$ Supine of LLL & 0.294 & $<0.001^{*}$ & 0.471 & $<0.001^{*}$ & 0.318 & $<0.001^{*}$ \\
\hline $3^{\text {rd }}$ Supine of LLL & 0.272 & $<0.05^{*}$ & 0.481 & $<0.001^{*}$ & 0.295 & $<0.05^{*}$ \\
\hline Femoral vein & 0.623 & $<0.001^{*}$ & 0.622 & $<0.001^{*}$ & 0.636 & $<0.001^{*}$ \\
\hline
\end{tabular}

As regards sex correlations, our study observed that highly significant positive correlations with great saphenous vein of the both lower limb in the different levels $\left(1{ }^{\text {st }}\right.$ Standing, $2^{\text {nd }}$ Standing $3 \mathrm{rd}$, Standing, $1{ }^{\text {st }}$ Supine, $2{ }^{\text {nd }}$ Supine and $3{ }^{\text {rd }}$ Supine as well as femoral vein. Interestingly, among these levels, the highest positive correlation found between $1{ }^{\text {st }}$ Standing, $2^{\text {nd }}$ Standing 3 rd Standing as well as femoral vein in female subjects $(P<0.001)$ (Table 2).

\section{Concerning age:-}

Our results revealed highly significant positive correlations with great saphenous vein of the both lower limb in the different levels $\left(1{ }^{\text {st }}\right.$ Standing, $2{ }^{\text {nd }}$ Standing 3 rd Standing, $1{ }^{\text {st }}$ Supine, $2{ }^{\text {nd }}$ Supine and $3{ }^{\text {rd }}$ Supine as well as femoral vein. Interestingly, among these levels, the highest positive correlation found between femoral vein and BMI, $(P<0.001)$

\section{Comparison between diameter of great saphenous vein of standing and supine position of the both lower limb in obese patients.}

Our results demonstrated significantly higher diameter ( $\mathrm{mm}$ ) of great saphenous vein at $1{ }^{\text {st }}$ Standing, $2^{\text {nd }}$ Standing 3 rd Standing in both lower limbs compared to corresponding levels in Supine position $(P<0.001)$ (Table 3).

Table3:- comparison between diameter of great saphenous vein of standing and supine position of the both lower limb in obese patients.

\begin{tabular}{|l|c|c|c|c|}
\hline parameter & Standing & Supine & T & P value \\
\hline $1^{\text {st }} l e v e l$ of RLL & $5.86 \pm 1.21$ & $5.1 \pm 1.215$ & 4.692 & $<0.05^{*}$ \\
\hline $2^{\text {nd }} l e v e l$ of RLL & $3.77 \pm 0.922$ & $3.01 \pm 0.92$ & 8.362 & $<0.001^{*}$ \\
\hline $3^{\text {rd }}$ level of RLL & $2.9 \pm 0.803$ & $2.1 \pm 0.803$ & 11.593 & $<0.01^{*}$ \\
\hline $1^{\text {st }}$ level of LLL & $6.1 \pm 1.215$ & $5.34 \pm 1.215$ & 4.692 & $<0.05^{*}$ \\
\hline $2^{\text {nd }}$ level of LLL & $4.01 \pm 0.92$ & $3.32 \pm 0.92$ & 8.362 & $<0.01^{*}$ \\
\hline $3^{\text {rd }}$ level of LLL & $3.5 \pm 0.803$ & $2.76 \pm 0.803$ & 11.593 & $<0.01^{*}$ \\
\hline
\end{tabular}


Receiver operating characteristic (ROC) curve for estimate the cutoff, sensitivity and specificity of femoral vein and great saphenous vein of the both lower limb in the different levels for differentiating obese from lean subjects.

We further investigated our results by ROC test, we found that among studied levels of great saphenous vein of the both lower limb in standing and supine position as well as femoral vein, the highest AUC (0.797, C.I 0.669 $0.924)$, sensitivity (96.1\%) and specificity (63\%) were of femoral vein diameter (mm) with cutoff $(7.15 \mathrm{~mm})$.

Table 4:- Receiver operating characteristic (ROC) curve for estimate the cutoff, sensitivity and specificity of femoral vein and great saphenous vein of the both lower limb in the different levels for differentiating obese from lean subjects.

\begin{tabular}{|c|c|c|c|c|c|c|c|c|}
\hline & \multirow[t]{2}{*}{ Cutoff } & \multirow[t]{2}{*}{ Sensitivity } & \multirow[t]{2}{*}{ Specificity } & \multirow[t]{2}{*}{ AUC } & \multirow[t]{2}{*}{ SE } & \multirow[t]{2}{*}{$\mathrm{P}$ value } & \multicolumn{2}{|c|}{$95 \%$ C. I } \\
\hline & & & & & & & $\begin{array}{l}\text { Lower } \\
\text { Bound }\end{array}$ & $\begin{array}{l}\text { Upper } \\
\text { Bound }\end{array}$ \\
\hline $1^{\text {st }}$ Standing of RLL & 6.7000 & $84.3 \%$ & $33 \%$ & 0.595 & 0.074 & 0.186 & 0.450 & 0.740 \\
\hline $2^{\text {nd }}$ Standing of RLL & 4.3000 & $80.4 \%$ & $38 \%$ & 0.600 & 0.073 & 0.162 & 0.457 & 0.744 \\
\hline $3{ }^{\text {rd }}$ Standing of RLL & 3.0500 & $70.6 \%$ & $42.1 \%$ & 0.582 & 0.072 & 0.256 & 0.441 & 0.723 \\
\hline $1^{\text {st }}$ Supine of RLL & 5.5900 & $76.5 \%$ & $42.2 \%$ & 0.595 & 0.074 & 0.186 & 0.450 & 0.740 \\
\hline $2^{\text {nd }}$ Supine of RLL & 3.3300 & $76.5 \%$ & $42.3 \%$ & 0.600 & 0.073 & 0.162 & 0.457 & 0.744 \\
\hline $3{ }^{\text {rd }}$ Supine of RLL & 2.7600 & $82.4 \%$ & $22 \%$ & 0.582 & 0.072 & 0.256 & 0.441 & 0.723 \\
\hline $1^{\text {st }}$ Standing of LLL & 6.7340 & $804 \%$ & $4.12 \%$ & 0.595 & 0.074 & 0.186 & 0.450 & 0.740 \\
\hline $2^{\text {nd }}$ Standing of LLL & 4.4240 & $76.5 \%$ & $41.1 \%$ & 0.600 & 0.073 & 0.162 & 0.457 & 0.744 \\
\hline $3{ }^{\text {rd }}$ Standing of LLL & 3.9950 & $76.5 \%$ & $32.1 \%$ & 0.582 & 0.072 & 0.256 & 0.441 & 0.723 \\
\hline $1^{\text {st }}$ Supine of LLL & 5.9740 & $80.4 \%$ & $41.3 \%$ & 0.595 & 0.074 & 0.186 & 0.450 & 0.740 \\
\hline $2^{\text {nd }}$ Supine of LLL & 4.3040 & $98 \%$ & $25 \%$ & 0.600 & 0.073 & 0.162 & 0.457 & 0.744 \\
\hline $3{ }^{\text {rd }}$ Supine of LLL & 3.2050 & $76.5 \%$ & $33 \%$ & 0.582 & 0.072 & 0.256 & 0.441 & 0.723 \\
\hline Femoral vein & 7.15 & $96.1 \%$ & $63 \%$ & 0.797 & 0.065 & $<0.001 *$ & 0.669 & 0.924 \\
\hline
\end{tabular}

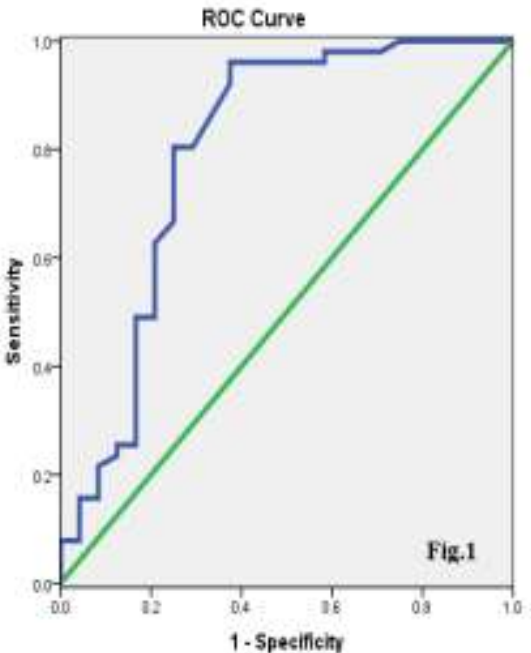

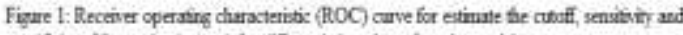

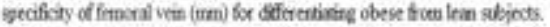

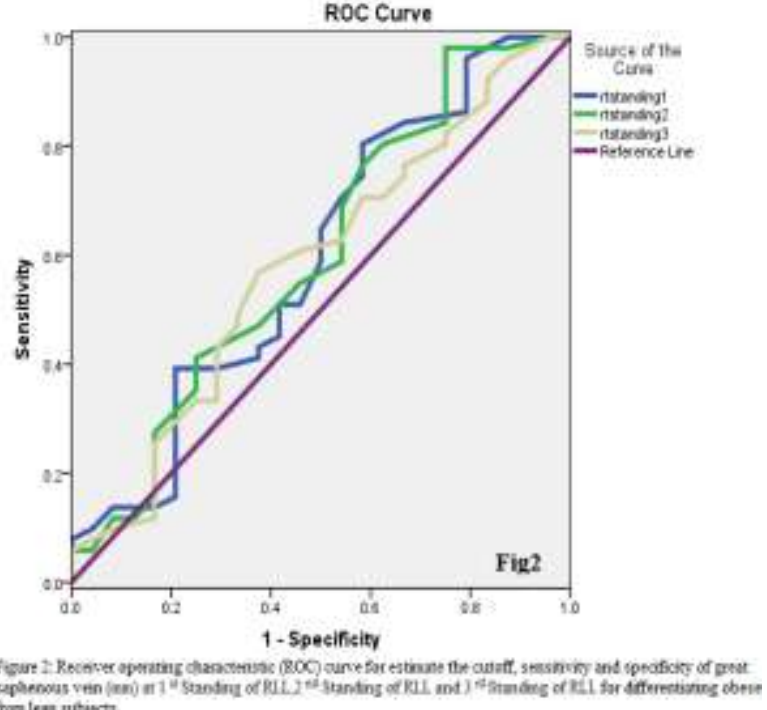

tronenoss vin 


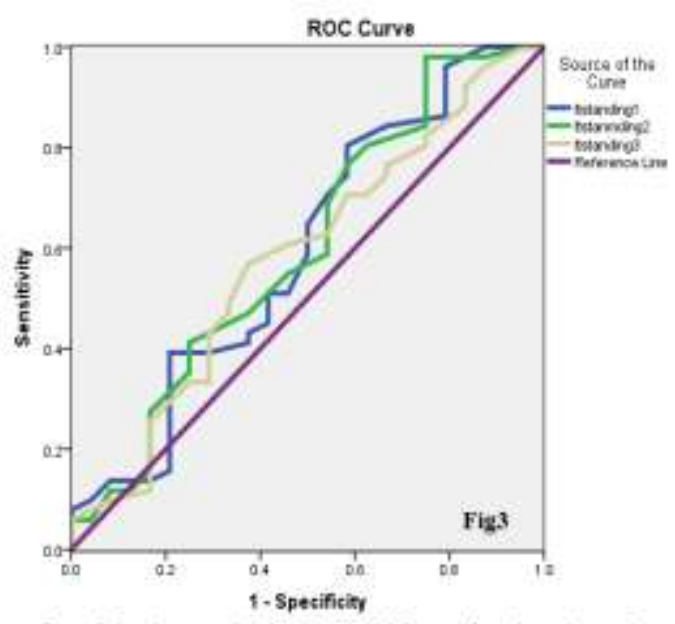

Figure 3: Rectever operatng chracteristic (BOC) arve for esthmate the cubce.

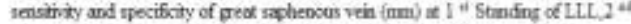

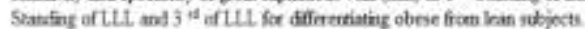

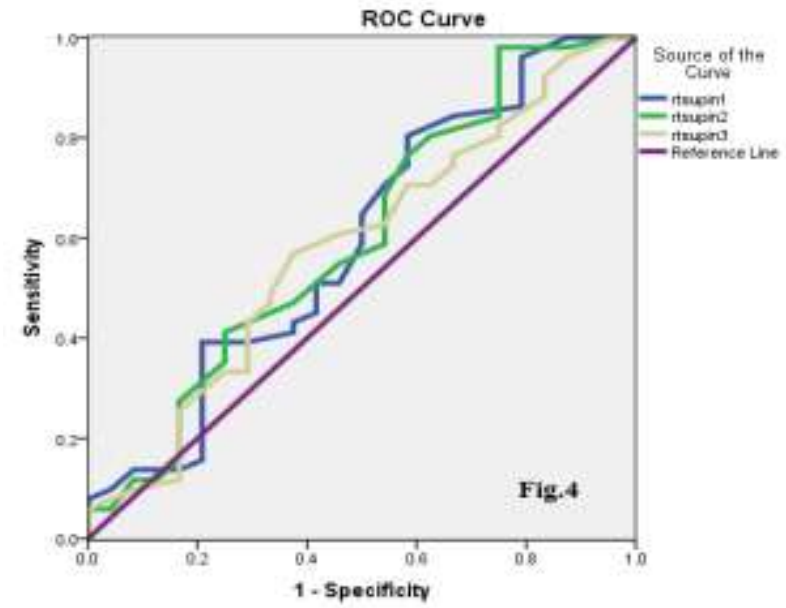

Figuret: Receiver operaing churacterissic (ROC) curve for estimate the cutoff, sensitiviry and specificity of great saphenous vich (uma) at I " Supine of RI L, 2 "s Supine of RI L and 3 a Supine of RL.1. for difinentiating obese frem kan vobjects.

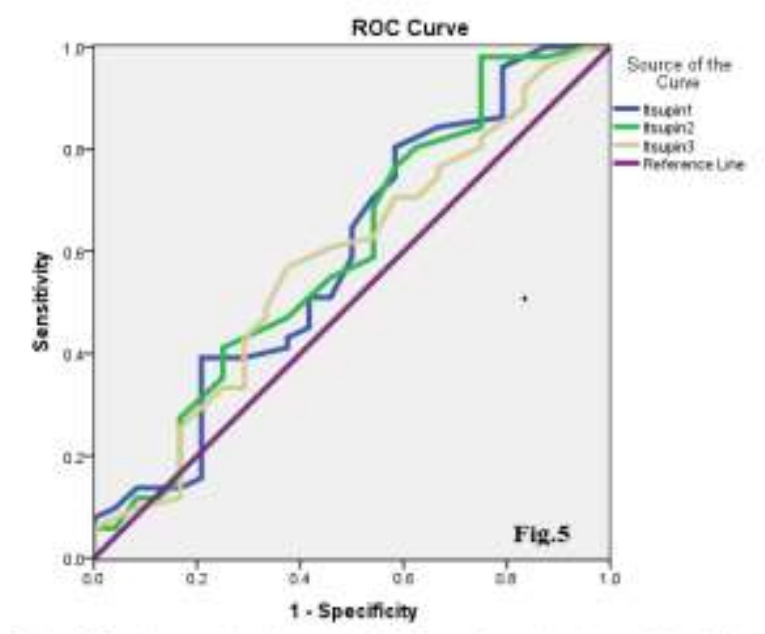

Figue 5: Receiver operating characteristic (ROC) carve for estamake the cutof, utesithity and

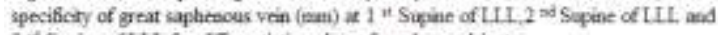

3 it Supine of LLIL for dfferentiating obese from lean sabjects.

Linear regression analyses in obese group to test the influences of the main independent variables against BMI (dependent variable).

linear regression analysis test found that, the diameter of femoral vein $(\mathrm{mm})$ was only independently correlated with BMI $(P<0.001)$.

Table 5:- Linear regression analyses in obese group to test the influences of the main independent variables against BMI (dependent variable).

\begin{tabular}{|c|c|c|c|c|c|c|c|c|}
\hline \multirow{2}{*}{\multicolumn{2}{|c|}{ Model }} & \multicolumn{2}{|c|}{$\begin{array}{c}\text { Unstandardized } \\
\text { Coefficients }\end{array}$} & \multirow{2}{*}{$\begin{array}{c}\begin{array}{c}\text { Standardized } \\
\text { Coefficients }\end{array} \\
\text { Beta }\end{array}$} & \multirow[t]{2}{*}{$\mathrm{t}$} & \multirow[t]{2}{*}{$\mathrm{P}$ value } & \multicolumn{2}{|c|}{$95 \%$ C.I } \\
\hline & & B & SE & & & & $\begin{array}{l}\text { Lower } \\
\text { Bound }\end{array}$ & $\begin{array}{l}\text { Upper } \\
\text { Bound }\end{array}$ \\
\hline \multirow[t]{5}{*}{1} & (Constant) & 31.804 & 4.077 & & 7.800 & $<0.001 *$ & 23.270 & 40.337 \\
\hline & Femoral vein $(\mathrm{mm})$ & 0.919 & 0.376 & 0.522 & 2.442 & $<0.05^{*}$ & 0.131 & 1.707 \\
\hline & $3^{\text {rd }}$ Standing of RLL & 2.321 & 1.821 & 0.718 & 1.275 & 0.218 & -1.490 & 6.132 \\
\hline & $1^{\text {st }}$ Standing of LLL & -0.880 & 1.920 & -0.411 & -.458 & 0.652 & -4.897 & 3.138 \\
\hline & $2^{\text {nd }}$ supine of LLL & -1.900 & 2.594 & $0-.674$ & -.733 & 0.473 & -7.330 & 3.529 \\
\hline
\end{tabular}




\section{Discussion:-}

Anatomical variation of the course and venous junction, presence of tributaries of the pudenda veins, Giacomini veins, presence of dilation and segmental reflux can be detected with color-flow duplex scanning, [12]. They also provide anatomical information about the GSV including size, patency, course, varicosities, double segments, and tributaries. [13].

The interesting finding of the present study is that, obese patients had significantly higher diameter (mm) of the femoral vein compared to lean controls. However, the diameter $(\mathrm{mm})$ of great saphenous vein of the both lower limb in the different levels ( $1{ }^{\text {st }}$ Standing, $2^{\text {nd }}$ Standing 3 rd Standing $1{ }^{\text {st }}$ Supine $2{ }^{\text {nd }}$ Supine and $3{ }^{\text {rd }}$ Supine) were nonsignificantly higher in obese women compared to lean subjects.

Similar to our study, Kügler et al. showed that increased body weight significantly correlates with higher venous pressure in lower extremities. Elevated venous pressure in obese subjects without any known venous pathology can be caused by several mechanisms. A possible explanation is their increased intra-abdominal pressure caused by the abdominal fa [14].

The study conducted by Amélia et al revealed that there were non-significant changes of great saphenous vein diameters in obese patients compared to lean subjects[15].

We analysis our findings by pearson correlation test, our results revealed that regarding BMI, our results demonstrated highly significant positive correlations with great saphenous vein of the both lower limb in the different levels $\left(1{ }^{\text {st }}\right.$ Standing, $2^{\text {nd }}$ Standing $3{ }^{\text {rd }}$ Standing, $1{ }^{\text {st }}$ Supine, $2{ }^{\text {nd }}$ Supine and $3{ }^{\text {rd }}$ Supine as well as femoral vein. Interestingly, among these levels, the highest positive correlation found between femoral vein and BMI.

In agreement with our study, Arfvidsson et al [16] demonstrated a reliable and significant correlation between iliofemoral venous and intra-abdominal pressure. Also, they observed that venous hypertension at the femoral vein and venous flow patterns similar to those in obese individuals can be induced in the non-obese by applying external abdominal pressure using a circumferential cuff placed around the abdominal trunk $[17,18]$.

As regards sex correlations, our study observed that highly significant positive correlations with great saphenous vein of the both lower limb in the different levels $\left({ }^{\text {st }}\right.$ Standing, $2^{\text {nd }}$ Standing $3{ }^{\text {rd }}$, Standing , ${ }^{\text {st }}$ Supine, $2{ }^{\text {nd }}$ Supine and $3{ }^{\text {rd }}$ Supine as well as femoral vein. Interestingly, among these levels, the highest positive correlation found between $1{ }^{\text {st }}$ Standing, $2^{\text {nd }}$ Standing $3{ }^{\text {rd }}$ Standing as well as femoral vein in female subjects.

Our findings are in concordance with our previous researches, the difference in incidence of dilated veins was statistically significant in women [ 19,20], after adjusted age, this association was not found in men. It was suggested that obesity acts as a promoter of varicose veins rather than a true primary risk factor [21].

Concerning age. our results revealed highly significant positive correlations with great saphenous vein of the both lower limb in the different levels ( $1{ }^{\text {st }}$ Standing, ${ }^{\text {nd }}$ Standing $3{ }^{\text {rd }}$ Standing, $1{ }^{\text {st }}$ Supine, $2{ }^{\text {nd }}$ Supine and $3{ }^{\text {rd }}$ Supine as well as femoral vein. Interestingly, among these levels, the highest positive correlation found between femoral vein and BMI.

On the contrary the findings conducted by Amélia et al found that aging is not necessarily associated directly with an increase in venous diameter of the deep and superficial venous system. The age-related increase in BMI was the most important determinant for an increase in diameter of veins in the standing position [ 15].

Even more importantly, we in this study attempted to pierce out that there were significantly higher diameter (mm) of great saphenous vein at $1{ }^{\text {st }}$ Standing, $2^{\text {nd }}$ Standing 3 rd Standing in both lower limbs compared to corresponding levels in Supine position.

In line with our results, Kröger et al observed that the cross-sectional area of the femoral vein and great saphenous vein as well as the volume increase in the standing position compared to supine position [22].

Orthostatic stress promotes translocation of thoracic blood volume into the compliant venous system of the legs, buttock and pelvis in humans [23,24]. This rapid fluid shift reduces central blood volume and represents a 
substantial cardiovascular stress, as reflected in reflex increases in heart rate and sympathetic nerve activity [25]. Thus, age-related changes of blood volume, sympathetic activity and venous compliance

In line with our results previous studies found that venous diameter in upright position is significantly greater in obese compared with non-obese subjects [24]. This supports the assumption that elevated intra-abdominal pressure caused by the elevated abdominal fat content is transmitted via the femoral veins to veins of the lower limbs and consequently leads to greater tension on the venous vessel wall, attenuating venous elasticity [24].

We further investigated our results by receiver operating characteristic curve(ROC) test, we found that among studied levels of great saphenous vein of the both lower limb in standing and supine position as well as femoral vein, the highest area under the curve (AUC) $(0.797$, C.I 0.669 - 0.924), sensitivity $(96.1 \%)$ and specificity (63\%) were of femoral vein diameter $(\mathrm{mm})$ with cutoff $(7.15 \mathrm{~mm})$. linear regression analysis test found that, the diameter of femoral vein $(\mathrm{mm})$ was only independently correlated with BMI.

\section{In conclusion:-}

Obese subjects had significantly higher diameter $(\mathrm{mm})$ of the femoral vein compared to lean control. However, the diameter $(\mathrm{mm})$ of great saphenous vein of the both lower limb in the different levels $\left(1^{\text {st }}\right.$ Standing, $2^{\text {nd }}$ Standing 3 rd Standing $1{ }^{\text {st }}$ Supine $2{ }^{\text {nd }}$ Supine and $3{ }^{\text {rd }}$ Supine) were non-significantly higher in obese women compared to lean subjects. Interestingly, the diameter of femoral vein $(\mathrm{mm})$ was only independently correlated with BMI. Indeed, further in-depth large studies are needed to estimate the cutoff, sensitivity and specificity of femoral vein and great saphenous vein in Egyptian population..

\section{References:-}

1. Shah DM, Chang BB, Leopold PW, Corson JD, Leather RP, Karmody AM. The anatomy of the greater saphenous venous system. J Vasc Surg. 1986; 3:273-83.

2. Zygmunt J., Jr What is new in duplex scanning of the venous system. Perspect Vasc Surg Endovasc Ther. 2009; 21:94-104. [PubMed]

3. Nüllen H, Noppeney T. Diagnosis and treatment of varicose veins: part 2: therapeutic procedures and results. Chirurg. 2010;81(12):1125-1138. German. [PubMed]

4. Hoballah JJ, Corry DC, Rossley N, Chalmers RT, Sharp WJ. Duplex saphenous vein mapping: venous occlusion and dependent position facilitate imaging. Vasc Endovascular Surg. 2002;36(5):377-380. [PubMed]

5. Davies AH, Magee TR, Jones DR, Hayward JK, Baird RN, Horrocks M. The value of duplex scanning with venous occlusion in the preoperative prediction of femoro-distal vein bypass graft diameter. Eur J Vasc Surg. 1991;5(6):633-636. [PubMed]

6. Wong JK, Duncan JL, Nichols DM. Whole-leg duplex mapping for varicose veins: observations on patterns of reflux in recurrent and primary legs, with clinical correlation. Eur J Vasc Endovasc Surg. 2003;25(3):267-275. [PubMed]

7. Cina A, Pedicelli A, Di Stasi C, et al. Color-Doppler sonography in chronic venous insufficiency: what the radiologist should know. Curr Probl Diagn Radiol. 2005;34(2):51-56.

8. Szendro G, Nicolaides AN, Zukowski AJ, et al. Duplex scanning in the assessment of deep venous incompetence. J Vasc Surg. 1986; 4:237-42.

9. Sarin S, Scur JH, Smith PD. Medial calf perforators in venous disease: the significance of outward flow. J Vasc Surg. 1992; 16:40-6.

10. Labropoulos N, Leon M, Nicolaides AN, Giannoukas AD, Volteas N, Chan P. Superficial venous insufficiency: correlation of anatomic extent of reflux with clinical symptoms and signs. J Vasc Surg. 1994; 20:953-8

11. Myers KA, Ziegenbein RW, Hua Zeng G, Matheus PG. Duplex scanning for chronic venous disease: patterns of venous reflux. J Vasc Surg. 1995; 21:605-

12. . Luccas GC, Nagase Y, Menezes FH, et al. Cirurgia de varizes dos membros inferiores: avaliação préoperatória do Sistema venoso com mapeamento duplex. Cir Vasc Angiol. 1996;12:15-20.

13. Ruoff BA, Cranley JJ, Hannan LA, et al. Real-time duplex ultrasound mapping of the great saphenous vein before in situ infrainguinal revascularization. J Vasc Surg. 1987;6:107-13.

14. Kugler C, Strunk M, Rudofsky G. Venous pressure dynamics of the healthy human leg. Role of muscle activity, joint mobility and anthropometric factors. J Vasc Res 2001; 38: 20-29 
15. Amélia C. Seidel, Fausto Miranda Jr., Yara Juliano, Neil F. Novo Relationship between the diameter of great saphenous vein and body mass indexJ Vasc Br 2005;4(3):265-9.

16. Arfvidsson B, Eklof B, Balfour J. Iliofemoral venous pressure correlates with intraabdominal pressure in morbidly obese patients. Vasc Endovascular Surg 2005; 39: 505-509.

17. Willenberg T, Schumacher A, Amann-Vesti B, Jacomella V, Thalhammer C, Diehm N et al. Impact of obesity on venous hemodynamics of the lower limbs. J Vasc Surg 2010; 52: 664-668.

18. Willenberg T, Clemens R, Haegeli LM, Amann-Vesti B, Baumgartner I, Husmann M. The influence of abdominal pressure on lower extremity venous pressure and hemodynamics: A human in-vivo model simulating the effect of abdominal obesity. Eur J Vasc Endovasc Surg 2011; 41: 849-855.

19. Coon WW, Willis PW, Keller JB. Venous thromboembolism and other venous disease in the Tecumseh community health study. Circulation 1973; 48: 839-46.

20. Widmer LK. Peripheral venous disorders, Basel III. Bern: Hans Huber,1978.

21. Callam MJ. Epidemiology of varicose veins. Br J Surg 1994; 81: 167-73.

22. K Kröger, C Ose, G Rudofsky, J Roesener, D Weil and and H Hirche Peripheral veins: influence of gender, body mass index, age and varicose veins on cross-sectional area Vasc Med 2003 8: 249.

23. Monahan KD, Dinenno FA, Seals DR, Halliwill JR. Smaller age-associated reductions in leg venous compliance in endurance exercise-trained men. Am J Physiol Heart Circ Physiol 2001; 281: 1267-73.

24. Smit AAJ, Halliwil JR, Low PA, Wieling W. Pathophysiological basis of orthostatic hypotension in autonomic failure. J Physiol 1999; 519:1-10.

25. Burke D, Sundlo"f G, Wallin BG. Postural effects on muscle nerve sympathetic activity in man. J physiol 1977; 272: 399-414. 